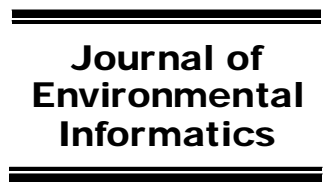

www.iseis.org/jei

\title{
Spatial Data Infrastructures in Africa: A Gap Analysis
}

\author{
Y. Guigoz ${ }^{1,2, *}$, G. Giuliani ${ }^{1,2}$, A. Nonguierma ${ }^{3}$, A. Lehmann" ${ }^{2,4}$, A. Mlisa ${ }^{5}$, and N. Ray ${ }^{1,2}$ \\ ${ }^{1}$ United Nations Environment Programme, Division of Early Warning and Assessment, Global Resource Information Database-Geneva, \\ International Environment House, 11 chemin des Anémones, Châtelaine CH-1219, Switzerland \\ ${ }^{2}$ University of Geneva, Institute for Environmental Sciences/enviroSPACE, 66 Boulevard Carl-Vogt, Geneva CH-1205, Switzerland \\ ${ }^{3}$ United Nations Economic Commission for Africa, Information, Science \& Technology Division, Menelik II Ave., Addis Abeba, Ethiopia \\ ${ }^{4}$ University of Geneva, Forel Institute, Uni Carl-Vogt, Geneva CH-1211, Switzerland \\ ${ }^{5}$ GEO Secretariat, 7 bis avenue de la Paix, Geneva CH-1211, Switzerland
}

Received 28 January 2015; revised 2 October 2015; accepted 16 October 2015; published online 9 December 2015

\begin{abstract}
The need for spatially explicit thematic data is currently increasing in parallel to the development of observing, storing and processing capabilities. This requires an integrated data management structure in which human and institutional aspects play a key role as part of a Spatial Data Infrastructure (SDI). We focus in this study on the African continent to evaluate the status of its SDI implementation. Because assessing SDI at a continental scale in a traditional way (i.e. following methods developed for national assessments) requires financial resources and mechanisms only affordable to developed countries (e.g. European Union), alternative ways have been explored based on fourteen key SDI indicators that were validated by SDI experts in a previous study. Data was collected for each African country through the African leading SDI institution (UN Economic Commission for Africa) and through Internet searches. We found relatively weak scores of the fourteen SDI indicators for African countries compared to the rest of the World, but with notable differences within Africa. We discuss the implication of the lack of information available on the Internet to assess SDI status in Africa. We conclude that it is necessary to improve statistical information in most African countries. This requires an agreed-on geospatial data structure and organization between concerned institutions that is only achievable through a shared global vision on geospatial data governance. To this end, we suggest a few quick wins and several new mechanisms that would enhance the flow of SDI statistical information and improve data management structure in Africa.
\end{abstract}

Keywords: SDI, Africa, Gap Analysis, monitoring, brokering

\section{Introduction}

Environmental issues cannot be solved solely at local, national, or regional scales without an integrated global approach (GEO, 2010). Furthermore, it requires a knowledge integration from various natural and social sciences as exemplified by Integrated Natural Resources Management (INRM) and Integrated Water Resources Management (IWRM) frameworks (Koch et al., 2013). Earth Observation (EO) and Geographic Information Systems (GIS) technologies have much evolved in the last decades to address this data challenge and to assist in environmental monitoring, modelling and analysis as demonstrated in climate change (Xia et al., 2014), ecosystem services (Yang et al., 2014), remote sensing (El-Askary et al., 2015) or water management (Su et al., 2013). They allow for example to answer the fundamental question on where to take action before any action is effectively taken. An

* Corresponding author. Tel.: +41 2291783 98; fax: +41 229178029.
E-mail address: yaniss.guigoz@unepgrid.ch (Y. Guigoz).

ISSN: 1726-2135 print/1684-8799 online

(C) 2017 ISEIS All rights reserved. doi: 10.3808/jei.201500325 interesting African example in the water domain is the ESA's TIGER initiative (ESA, 2013) that uses satellite observations to inform local authorities about the state of this vital resource. Another African example is the SERVIR-Africa (2014) project that monitors and forecasts ecological changes and responds to natural disasters. At the global scale, an increasing number of useful Earth Observation products exist: the NASA Shuttle Radar Topographic Mission (USGS, 2010), the ESA global land cover map (ESA, 2014), the FAO Global Soil Map, the UNISDR Global Risk Data Platform (Giuliani and Peduzzi, 2011), or the daily ice extent from the University of Illinois (2014). A downside of these products is the sheer amount of data produced, which requires growing storage and management capacities (Mazzetti et al., 2014).

Despite wide availability and use of EO and GIS tools, access to quality environmental and geospatial data remains the largest challenge for supporting decision-making. A plea was made at the Rio Conference twenty years ago for spatiallly-explicit data to address global environmental issues (Clarke, 1999). This is even more important today, as the integration of environmental data at various spatial and temporal scales is necessary to better understand our global system and take appropriate actions. If geospatial data are necessary 
for tackling many environmental challenges in developed countries, it is even more so in developing countries where high demographic rates is combined to massive rural exodus, water or power shortages. In emergency situations, quality data is also crucial as demonstrated after the 2010 Haiti earthquake (UNITAR, 2014). According to EIS-Africa, sustainable development of a particular village, city, province, or country requires access to data about the environment (EIS-Africa, 2002).

Data availability is the first step, but accessibility to this data (and associated metadata) by all stakeholders is what can really make a difference. Data must be shared to facilitate its integration with other datasets, and to produce integrated knowledge. But data production, access, use and dissemination are dependant on many other factors such as related laws, regulations, standards, infrastructure, and human factors. This justified the development of Spatial Data Infrastructures (SDI) for efficient geospatial data workflow and management. A commonly accepted definition of an SDI is "the relevant base collection of technologies, policies and institutional arrangements that facilitate the availability of, and access to, spatial data" (Nebert, 2008). Furthermore, Rajabifard (2002), Giuliani and Peduzzi (2011), and Giuliani et al. (2013) distinguish the following five main SDI components: Data (geospatial data), People (human resources), Access network (networking technology), Policy (institutional framework) and Standards (technical standards).

\subsection{Local, National and Continental SDIs: Availability and Access}

A SDI can be established at different levels, ranging from local to national, continental or global levels. A local SDI typically focuses on detailed datasets of small geographic extent for use at local scale. On the other side of the scale, a global SDI fosters global datasets, generally at lower resolution.

Rajabifard et al. (2000) introduced the notion of hierarchical relationship between these different geographic levels of SDI. Each of these different SDI levels has an influence on the upper ones. For example, a National SDI (NSDI) should theoretically provide access to contents of the local SDIs within the country. But this requires a well-organized architecture, both at technical and institutional levels, which is only possible through a National Policy. This is even more needed at higher levels such as continental or global. Setting up such policies at supranational levels is very challenging and requires strong political integration and willingness.

One of the best examples of such a continental SDI is the European INSPIRE directive (European Parliament, 2007) that seeks to establish a spatial information infrastructure for the European Union to support environmental policies, and policies or activities that have potential impacts on the environment. The INSPIRE extent groups the European Union countries plus some other voluntary, European non-member states (e.g. Switzerland, Turkey) (European Commission, 2013).

It is now well recognized that regional and national SDIs can greatly benefit users at different governmental levels. For any SDI implementation, having these five components correctly taken into consideration and adequately implemented creates favourable conditions for production of, access to, use and dissemination of geospatial information. In turn, these favourable conditions of data flow will feed the data needs for informed decisions in many sectors of the society and will be a real added-value for many societal building blocks (Masser, 1998), (Rajabifard et al., 2000). According to the Federal Geographic Data Committee (FGDC, 2014), a NSDI allows reducing the duplication of effort among agencies, improve quality and reduce costs related to geographic information. It makes geographic data more accessible to the public, increases the benefits of using available data, and establishes key partnerships with states, counties, cities, tribal nations, academia and the private sector.

\subsection{SDI Assessment}

The adoption of SDI principles and technologies is far from being equally acknowledged in all parts of the world. Countries such as USA, Australia, Canada, or Germany have been pioneers in adoption of SDI concepts (Monett et al., 2013) with well advanced NSDI strategies, whilst most other countries are at various stages of adoption and implementation, with many still lacking tangible initiatives or institutions to lead the effort. It is therefore important to be able to map out national or regional performance in developing and implementing SDI capacities (Giff, 2006). Several authors (Delgado Fernandez et al., 2005; Eelderink, 2006; Steudler et al., 2008; van Loenen et al., 2008;Vandenbroucke, 2009) have worked on developing various SDI assessment frameworks. A chosen methodology for SDI assessment highly depends on the geographic extent of the study. Measuring SDI at national or sub-national level is very different from measuring SDI at a continental level for which time and money constraints are a major limiting factor.

\subsection{The Case of Africa}

Endowed with abundant and diversified natural resources, Africa requires appropriate tool to manage the resources, more so as it is facing major pressing issues such as climate change impacts and environmental stresses. The continent could particularly benefit from an integrated SDI implementation at national, regional and continental scales. Among other reasons that plead in favour of such underlying assumption include: (1) environmental pressure is increasing very fast and necessitates urgent solutions for which multi-disciplinary and transnational environmental data is needed; (2) technical infrastructures are emerging and the time is right to have SDI concepts and tools adopted; (3) there is a great opportunity from the proximity to Europe and its advanced SDI involvement (e.g., INSPIRE directive, participation in many projects promoting SDI particularly in Africa); (4) several SDI actors and initiatives already exist in Africa (see note SN1).

An assessment of the current status of SDI implementation 
in Africa and an analysis of where the gaps are at continental scale is therefore needed. The objectives of this study are then:

i) to examine innovative way of performing SDI assessment, notably by making extensive use of Internet searches and using the existing networks of SDI actors;

ii) to assess the SDI implementation in Africa through indicators and assessment variables that take into account all the SDI components; World;

iii) to compare the African situation to the rest of the

iv) to suggest some ways for improving the SDI implementation and monitoring in Africa.

\section{Methodology}

\subsection{Review and Choice of SDI Assessment Frameworks}

There are currently five main existing SDI assessment frameworks: (1) the SDI Readiness Index (Delgado Fernandez et al., 2005), (2) the organisational maturity matrix (van Loenen et al., 2008), (3) the performance indicators (Steudler et al., 2008), (4) the INSPIRE \& NSDI State of Play methodology (Vandenbroucke, 2009), and (5) the set of fourteen key indicators to assess NSDIs in developing countries (Eelderink, 2006).

The SDI readiness index is not appropriate for the African case as it aims at scoring an individual country, which is not meant for study and comparison at continental level. The theory behind organisational maturity matrix combines organisational indicators with development stages, which again does not make it appropriate for a quantitatively measurable continental study, as it would require considerable time to evaluate each country's development stage. Thirdly, Steudler's performance indicators is related to land administration and only gives a broad framework with some possible general indicators for evaluating SDIs, which is not appropriate at continental scale. The core of the INSPIRE \& NSDI State of Play methodology is about collecting information from websites, documents and experts. Eelderink's fourteen key indicators for assessing NSDIs have been validated by experts; besides, this reasonably low number of indicators makes it possible to gather sufficient data to perform a meaningful study at the African scale. As the goal of a SDI continental assessment in Africa is similar to the one of INSPIRE, which is to monitor the implementation of INSPIRE (Vandenbroucke, 2009), we decided to follow this methodology in combination with Eelderink's fourteen indicators to assess NSDIs in developing countries. Eelderink groups these key indicators by SDI component, including an additional "Other" component (see Table ST1).

\subsection{Targeted SDI Levels}

Even if we aim at assessing the continental status of SDI implementation in Africa, the reference level remains countries as most statistics are produced at this level. For the INSPIRE directive in the European Union, the national level is crucial for coordination and implementation (Vandenbroucke, 2010) as National SDI have a full impact on all levels of the SDI hierarchy (global, regional, state/provincial and local) (Eelderink, 2006). With data for particular SDI indicators at country level, it becomes easy to (1) make continental statistics (e.g., mean, standard deviation), (2) compare the continent to other continents or to an ideal situation, (3) compare continental sub-regions with each other, and (4) compare countries with each other.

\subsection{Selected African SDI Champion Institution}

There is no formal SDI body at a continental level in Africa, as it is the case in the European Union with the infrastructure for Spatial Information in Europe (INSPIRE) or in the USA with the Federal Geographic Data Committee (Makanga et al., 2010). However, the UN Economic Commission for Africa (UNECA) plays a key role in Africa in terms of advancing SDI in the continent (Schwabe et al., 2009). For example, the Committee on Development Information, Science and Technology (CODIST) (UNECA, 2013) meeting, held every two years in Africa and organized by UNECA, allows African countries to officially gather around the SDI thematic, in order to advance the SDI agenda in Africa through the resolutions voted during the meeting. Besides CODIST, the ICT department of UNECA performs many actions to promote SDI across Africa (e.g. SDI information collection, conferences and workshops). UNECA is therefore the continental institution of choice to help collecting appropriate data on SDI in addition to information gathered on the Internet.

\subsection{Sources of Assessment Data}

Information provided by UNECA mainly comes from a survey among African countries performed in 2011 (see Figure SF2). According to UNECA, 25 of the 53 contacted countries replied to this survey. We re-used UNECA's survey for the following reasons: (1) to our knowledge the UNECA questionnaire is the only existing one on SDI covering all African countries, with the same set of questions, which makes the answers comparable; (2) we consider the commitment of African countries' to UNECA to be better than to other organizations, which impacts the level of responsiveness to the questionnaire; (3) using a single survey should minimize misinterpretation of the meanings of used terminologies that may be different among surveyors. In addition to the UNECA survey, Internet searches and online databases were used for the assessment.

\subsection{Selected Assessment Variables for the $\mathbf{1 4}$ Indicators}

The proposed methodology consists in gathering information from UNECA and from various sources on the Internet at national level, and in selecting and organizing information based on fourteen key indicators defined by Eelderink (2006).

In order to perform quantitative SDI comparisons, it is necessary to gather values for each of these key indicators. This requires defining specific variables, or sometimes proxy vari- 
ables, to measure the key indicators. The methodology and sources of information for measuring each of the 14 key SDI indicators can be found in the online supplemental material (see note SN2).

Among all the proposed variables, some can be considered as "variables of objectives" allowing to concretely measure the current status of an SDI component. The others are "variables of means" to reach the quantitative objectives in longer term by creating a favourable environment. For example, the number of people who attended the CODIST 2011 meeting is a countable variable of objective, while the socio-political stability index is a variable of means that helps in assessing the general SDI environment. The variables of means can be considered as input variables for creating a favourable SDI environment. The variables of objectives are the countable results of SDI status, objectives to measure and improve; these are considered as output variables. The key indicators, assessment variables, type of variables and sources used can be vizualised in table ST2.

\section{Results}

The results for each assessment variable can be visualised in an online table with reference sources at http://africa-sdi. grid.unep.ch. They are also summed up at the bottom of each indicator's column by continent when possible or for Africa only. The continental results are expressed either as a percentage or as a real value depending on the indicator. The detailed results description by indicator is available in the supplemental note SN3.

The SDI's “data” component results were very weak in Africa (11\%) compared to the 87 100\% data availability reported for Europe (Vandenbroucke, 2011). In the "people" SDI component, the "capacity building” key indicator revealed a huge gap for GIS and SDI capacity building in Africa compared to the ideal situation where most countries of a continent should at least have a few institutions teaching GIS to increase local capacity. For the "willingness to share" indicator, neither information about existing data sha- ring policies nor any national geoportal could be found in Af- rican countries. Only memberships of international SDI initia- tives could be evaluated, which places Africa in the same position as Asia and the Americas. All the variables measured for the "Human capital" and "SDI awareness" key indicators show that Africa is lagging behind the other continents. The la- tter revealed a low number of Internet users in Africa despite a growing but still low number of active mobile-broadband subscribers, and low attendance of African countries in key continental SDI meetings (CODIST). Based on the measurements performed on the four key indicators of the "people" SDI component, Africa has the lowest value of all continents.

The "Access network" SDI component measured through the defined assessment variables of the "access mechanism" key indicator revealed that Africa is in crucial need of improving its information infrastructure and ICT services in order to properly implement SDI.
The "Policy" SDI component measurement in Africa revealed difficulties to track information on SDI funding policies or even on ICT expenditure for the "funding" key indicator. The key indicators "vision", "institutional arrangements", "leadership" and "socio-political stability" are also low compared to other continents. The supplemental Figure SF4 shows the details by country of the political stability index, with Africa less socio-politically stable than other continents.

Regarding the "standards" SDI component, information we found for the indicator "metadata availability" for fundamental datasets in Africa was scarce, making it difficult to draw a general trend. In terms of "interoperability" indicator assessment, only a few countries reported national working groups on standards, but about half of the African countries are compatible with the African geodetic Reference Framework, which is encouraging but still low. Unfortunately, no African institution was member of the leading geospatial standards institution (OGC) as of February 2013.

Finally, regarding the "Other" SDI component defined by Eelderink et al. (2008) and associated "initiatives connected to SDI” indicator, the GEO membership of African countries is comparable with other continents, as well as the availability of African data in portals of international SDI initiatives such as GEOSS, EyeonEarth, One Geology or GBIF.

\section{Discussion and Perspectives}

\subsection{Innovative Way of Performing SDI Assessment}

As a continental SDI implementation assessment is different from a national or sub-national assessment, a specific assessment framework is needed. This has so far only been done in Europe through the INSPIRE State of Play, the goal of which is to describe, analyze and assess the status of INSPIRE and NSDI implementation in 34 countries in Europe (Vandenbroucke, 2011). The assessment framework used in INSPIRE State of Play could not be directly transposed to Africa for the following reasons:

(1) The INSPIRE State of Play aims at monitoring on a permanent basis the implementation of the INSPIRE directive in Europe that addresses 34 spatial data themes needed for environmental applications (European Commission, 2014). The INSPIRE infrastructure in the member states does not necessarily equate the National SDIs (e.g. these might also cover other sectors such as agriculture, spatial planning, or additional technological components) (Vandenbroucke, 2009). For Africa, we do not want to measure the implementation of a particular directive but we want to measure the general SDI components in each country. Even though we followed the business approach of the INSPIRE State of Play, we adapted it to a more NSDI-oriented approach. This is the reason why we completed it with the SDI assessment framework of Eelderink (2006).

(2) In the INSPIRE State of Play, the indicators shall be collected by each Member State on an annual basis and the results must be made public. This is not possible in the African 
context where there is no political integration such as the European Union and hence no binding directive such as INSPIRE to request indicator collection from member states.

(3) The resources available for this study did not allow a deep institutional analysis such as in the INSPIRE State of Play. The assessment indicators proposed by Eelderink have the advantages of (1) targeting developing countries, (2) being validated by SDI experts based on case studies in Latin America, Asia and Africa, and (3) consisting in a reasonable number of indicators. For measuring these 14 indicators, Eelderink performed a detailed assessment on six case studies. This detailed assessment was possible given the low number of countries, but in the present assessment we want to have a general overview of the SDI situation in 54 African countries. We performed then a lighter assessment of each country, based on assessment variables different from Eelderink but still relevant for populating the 14 indicators required.

The main bottleneck of such an assessment is the difficulty to obtain data for some assessment variables due to the large number of countries and heterogeneous availability of SDIs information, both on the Internet and in the SDI champion institution. At the same time, this opens the way to new synergies and mechanisms needed to improve the data availability, between the SDI continental institution and the concerned countries. This is where the political aspects come into play and it is then crucial to improve the SDI implementation status in Africa.

The assessment framework we have used is innovative in the sense that it combines a proven methodology for collecting information used at continental scale in Europe (INSPIRE State of Play) with SDI assessment variables validated by experts used at national level. Moreover, it is the first time that an SDI assessment at the African scale has been performed.

\subsection{SDI Assessment}

The performed analysis highlighted several trends regarding SDI status in Africa: (1) Africa has the lowest ranking of all continents (except Oceania) in most key variables assessed when an international comparison is possible; (2) for the variables that are only assessed in Africa, most of the results show a very weak SDI status; (3) there is a serious difficulty in finding data about SDI key indicators and assessment variables in Africa on the Internet and even at UNECA, considered as a key institution in Africa for SDI-related information. This makes the SDI monitoring at a continental level not reliable yet, not only in Africa but also worldwide with notable regional differences (e.g. data for European Union countries are easier to find thanks to INSPIRE monitoring).

Getting such information at country level is already a challenge, as it requires a deep analysis, often dependent on the accuracy of national surveys or on the good-willingness of people in the governments providing information. At a continental level, it is even more challenging as a coordinating body (UNECA in the case of Africa, the European Commission through the INSPIRE directive in the European Union) needs to gather data of all member countries. There seems to be an obvious lack of a standardized mechanism that would allow for regular provision of SDI monitoring data. Such mechanisms exist in other fields like economy or health. For example, a lot of health-related data are available at the World Health Organization's website (WHO, 2013), allowing for countries monitoring and comparison. Similarly, the World Bank's website (World Bank, 2013) provides valuable economic indicators. This makes these domains' monitoring much convenient and allows for targeted improvement of the concerned indicators. In the case of WHO, this could be explained by the membership of all the countries and a well-structured organization, with a clear global mandate for health coordination role. Such a global mandate is delivered by the member states through the United Nations. SDI being interdisciplinary by nature, the coordination role is not clear yet in most places of the world. This is being addressed more and more at national level through NSDIs but is still lacking at continental (except in the European Union with INSPIRE) or global levels. Unfortunately, this prevents an optimal targeting of SDI efforts in a specific area or continent.

The WHO example just mentioned and the successful European SDI through the INSPIRE directive both result from a political consensual decision (at UN level in the first case, at European level in the second case) leading to a successful mechanism of data production and monitoring. This necessitates a political will that remains to be strengthened across Africa and might be one of the causes that lead to a lack of a common SDI African vision. This translates into weak SDI commitments in African countries, even though UNECA plays its coordinating role in organizing SDI continental meetings such as $\mathrm{CO}$ DIST or other SDI-related events. The weak attendance to the CODIST meetings (about 50\% of African countries) confirms this lack of commitment.

However, there is hope that grouping of African countries such as the 15 countries within the Economic Community of West African States (ECOWAS) may trigger a sub-continental organized environmental data and information infrastructure. This is already the case in the energy sector with the ECOWAS Observatory for Renewable Energy and Energy efficiency (ECOWREX) that is currently redeveloping its rich map viewer (ECOWREX, 2014).

Further initiatives such as AfriGEOSS (GEO, 2014) may raise awareness on the benefits of SDI and promote national commitments for the implementation of SDIs in the continent. This analysis also revealed important intra-African differences with some African countries always in the head group for all the assessed variables: South Africa, Algeria and Botswana. In some cases, Egypt and Tunisia have also relatively good scores. The score of these five countries for some of the assessed variables can be visualised in the table ST3 along with a deeper analysis of the intra-African differences (note SN4).

A combination of all the assessed variables into one single value of SDI status per African country would be interesting for comparison. The types of assessment variables being different by nature makes it difficult to combine them together to give a unique value by country. However, one type of variables 


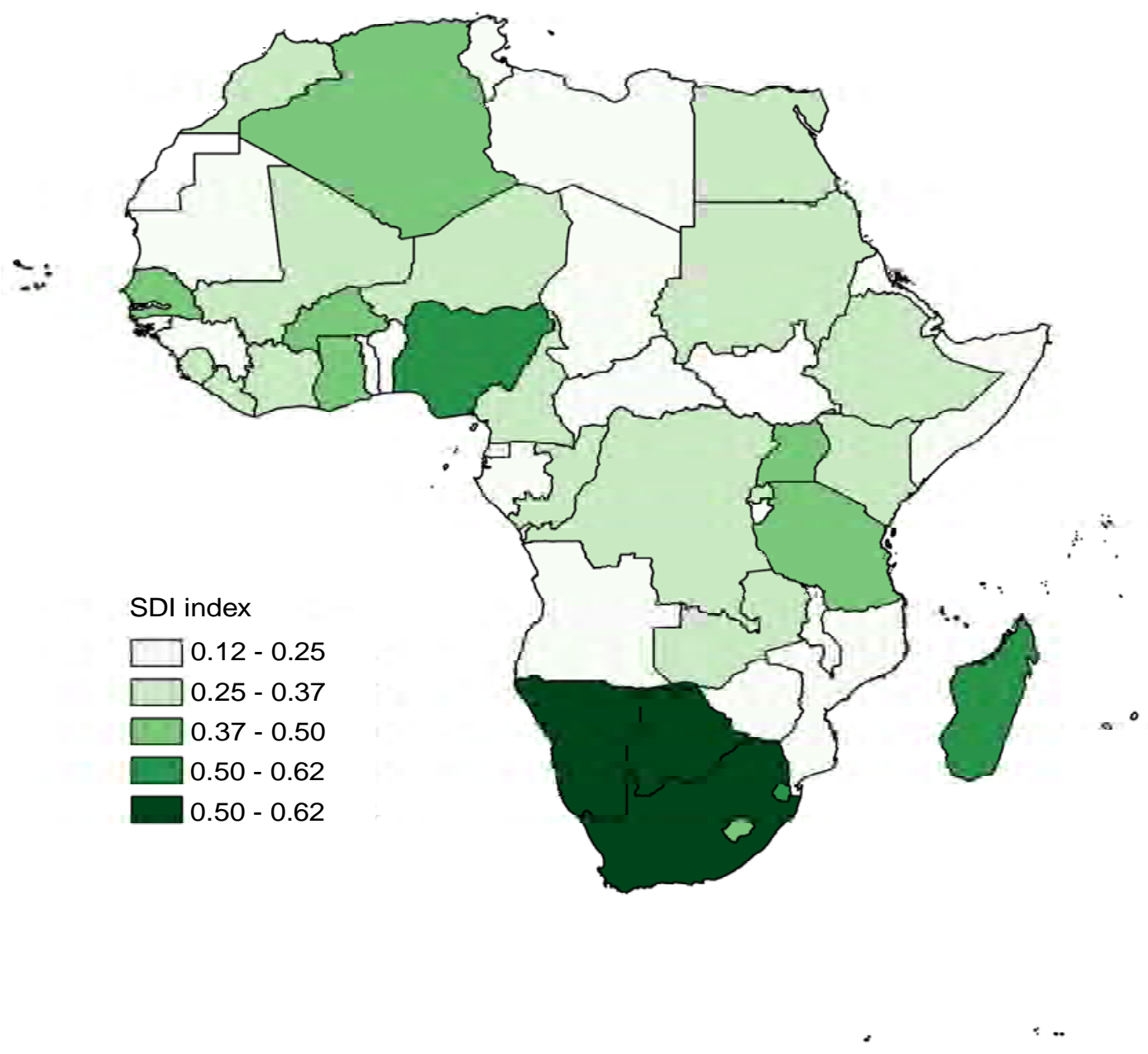

Figure 1. Changes in the reaction pathway for biosolids destruction by integrating the MEC reactions in anaerobic digestion (MEC: microbial electrolysis cell).

can be combined to obtain an indicative value by country, which can then be mapped to better visualize the SDI status in Africa. This has been done for the "objective variables" (or output variables) and is available both on the online table for the numbers (http://africa-sdi.grid.unep.ch) and in the Figure 1 for the map. It shows the same trends as the ones discussed just above, with South Africa, Botswana and Namibia outstanding, while Algeria, Nigeria and Madagascar perform quite well also.

The methodology used for building the index is detailed in the supplementary note SN5. Among the issues discussed so far, two main elements should be retained in terms of SDIs in Africa: (1) National SDIs need to be much improved in Africa and (2) there is a crucial need for better data to monitor the SDI status through assessment variables described in this article.

\subsection{African Situation to the Rest of the World}

As shown in the results section and illustrated at http://afr
ica-sdi.grid.unep.ch/SDI_variables_display_region.php, Africa scores less than other continents for most SDI-related variables measured, except the percentage of GDP spent in ICT and the official adoption of metadata standards. This necessitates a comparison with other regions where the SDI implementation status is much better, in order to find out if some elements would be transposable to Africa.

Europe is regularly mentioned as a successful example of a continental SDI implementation thanks to its federated approach legally bound through the INSPIRE directive. The most visible result of this enterprise is the European "INSPIRE geoportal” (European Commission, 2013), gateway to European member states services (data and metadata). Regular reviews and reporting of the SDI status like the INSPIRE State of Play allow maintaining and improving this mechanism, resulting in much SDI metainformation available. The strong European political commitment that led to the INSPIRE directive has been key. Getting such political signal in other parts of the World, in particular in Africa, requires political integration and com- 
mon vision that are not consolidated enough yet.

Idrees (2012) compared approaches and strategies for NSDI implementations between the developed and developing World, and found out that political and ethnic polarity are visible key factors observed with the developing countries hindering speedy implementation of policies. He also states that successful and sustained SDI implementation will largely depend on the political will of the leaders. If this is already the case at national levels, it is even more so at a continental level. The African political body likely to initiate a continental political will in terms of SDI integration is the African Union. But even if this was on top of its agenda, it does not have the same powers as the European Union to pass a binding directive to its member states such as INSPIRE. This means that the European model cannot be directly transposed to Africa given the different political structure of the key institutions. Nevertheless, even if a strong political integration is lacking on the continent, alternatives exist to improve SDI and SDI monitoring with assets already available in Africa.

\subsection{Suggestions for Improving the SDI Implementation and Monitoring in Africa}

First of all, in terms of standardized geospatial data availability, a system of systems approach instead of a federated approach would have the advantage of lowering the constraints on the side of the data producers. Indeed, in a system of systems approach, it is not necessary for the data producers to modify their standards in order to align with a mandatory standard as it is the case in the federated approach. This is the role of a mediator, a so-called broker, to perform the matching between the input standard available and the output standard needed. This brokering approach (Nativi et al., 2009), (Nativi et al., 2012) and related GI-cat tool (ESSILab, 2014) have been notably adopted by the GEOSS and the Earthcube partnership (http://earthcube.org) as a backbone for their catalogue infrastructures. This approach and tool should ideally be adopted at a central African SDI institution if it is to become the continental reference system serving the African geospatial data in a harmonized way. The presence of UNECA to play such a role in Africa is a strength that needs to be used. This has been done in the framework of EU FP7 funded projects Afromaison (2011) and EOPOWER (2014). The GICat has been implemented in Afromaison to broker existing African resources, while it has been customized and transmitted to UNECA in the frame of EOPOWER to become an African broker (Afromaison, 2013). This will also have the advantage to allow many organisations that informally contribute to SDI development even though they do not have the mandate (Makanga et al., 2010) to uptake their geospatial information.

In terms of SDI monitoring on the continent, UNECA is an asset as it is the recognized continental institution and already performs SDI monitoring surveys. These are currently weakened by the lack or imprecise answers of some countries. Two elements could be taken into consideration to improve the SDI monitoring survey from UNECA. The first one would be to set up an online database at the UNECA website, automatically populated by online forms submitted by National Mapping Agencies through an online survey form, which would allow an easier populating, management and sharing of basic SDI information. This could be started with at least a few variables and then extended to more variables later. The lack of motivation of stakeholders at national levels to fill such online surveys could be the main barrier, but overcoming this could be done through (1) an increased awareness of being an essential node of an integrated continental effort, (2) a kind competition with other countries to better position their own country in terms of SDI information provision, (3) the promises of the reduction in the number of dispersedly or redundant requests for information.

The second element to improve SDI monitoring in Africa is the example of "data flows" scoring for each member country of the European Environment Information and Observation Network (EIONET, 2012). On a simple webpage it is possible to see which country does better than the others in terms of environmental indicators reporting. When clicking on a given country, a graphical appreciation (with a given number of smileys) of progress is shown for each monitored indicator compared to the previous year. This allows to directly appreciating where to concentrate efforts and stimulate countries to improve significantly. A similar mechanism for SDI indicators and related assessment variables monitoring would be interesting to put in place at a continental level. Such an assessment, as well as a list of national geo-portals of the continent (Najar et al., 2007) and other SDI relevant elements could be the components of a dedicated "SDI section" of the UNECA's website, giving African SDI much more visibility and awareness to create a positive dynamism.

Another important asset of Africa is its participation in many projects and initiatives, past or on-going, that have a strong SDI or Earth Observation component, e.g. AEGOS (2011), Africover (FAO, 2013), EIS-Africa (2014), Geonetcast (GEO, 2013), FEWS NET Africa Data Portal (USGS and USAID, 2013), SAFARI2000 (NASA, 2013), SERVIR-Africa (2014), SDI-Africa monthly newsletters (GSDI, 2012) and mailing list (GSDI, 2011). The recently launched AfriGEOSS initiative, developed in the GEO framework, aims to enhance Africa's capacity for accessing, producing, using and managing Earth observations data and information. This will be achieved through implementing a coordination framework taking into account, national, regional and continental level. Under the coordination network periodic user needs and status of data access and products development will be undertaken at national and regional level, thereby informing the continental status. It is thereby expected that AfriGEOSS will add great value to the implementation and monitoring of SDI in Africa.

Moreover, the results of the search of African data in portals such as GEOSS, GBIF, and OneGeology showed that Africa is quite well connected to current SDI-related initiatives, which is a positive push for complying to SDI international standards and therefore for improving African SDI initiatives. This African integration in international cooperation projects 
is an opportunity that allows the continent to remain in a dynamic of best practices in terms of SDI, as in the example of the African broker made possible by international projects. This should continue to be used for addressing the different issues in view of better implementation of SDI and SDI monitoring on the continent.

The concept of "open data" means that data should be freely available to everyone without restrictions (copyright, patents or control) (Wikipedia, 2015). This concept should also be further investigated to set up a better data flow and automatic mechanism of SDI statistics and key indicators. Indeed open data, not restricted by passwords, becomes more easily accessible by web services for direct parsing by machines without human intervention and hence give live access to data. This approach is for example used by the new UNEP monitoring system called "UNEP Live" (UNEP, 2014). A same live data flow for SDI statistics and key indicators would be a very valuable added value for SDI live monitoring.

Such open approach to data seems obvious but is unfortunately far from being the norm even though more and more open data initiatives exist. A very encouraging example of the fight against the lack of data is the "Open data for Africa" (African Development Bank, 2014) platform, financed by the African Development Bank (AfDB), that hosts open data for all 54 African countries since July 2013. Coupled with free and open source GIS technologies, this could really help better flow of data and less financial and institutional barriers.

In terms of capacity building, there is also a lot of work to do for GIS and SDI education. E-learning with initiatives such as UNIGIS international association (UNIGIS, 2014), the growing number of "Massive Open Online Courses” (MOOC) provided by universities worldwide, or material developed in various projects like "Bringing GEOSS services into practice" (Giuliani et al., 2014) are solutions that could be more broadly used in the short to middle term to address the GIS education shortage existing in Africa.

\section{Conclusions}

\subsection{Innovative Way of Performing SDI Assessment}

The first objective of this study was to examine an innovative way of performing an SDI assessment, at the continental scale. The methodology chosen and described addresses this objective since the assessment framework used combines a proven methodology for collecting information used at continental scale in Europe (INSPIRE State of Play) with SDI assessment variables validated by experts and usually used at national level. This methodology allows making use both of the Internet global search possibilities and a continental expertise (UNECA). Combined together, they provided necessary data for a continental SDI implementation measurement. The main limitation is due to the lack of data both on the Internet and at the SDI champion institution. This has to be solved at the political level, for example through the African Union, by a more binding directive on the model of the INSPIRE directive for the European Union. The assessment varia- bles proposed in this study are a first attempt for populating a suite of appropriate indicators and give a first overview of the African status of SDI implementation.

The second objective was to perform the evaluation of SDI status in Africa using assessment variables defined further to the methodology chosen. This revealed a weak status of SDI implementation in Africa, but suggestions and opportunities were also discussed to address this situation. This assessment also showed the difficulty in finding reliable data for measuring the assessment variables on the Internet or at the SDI key institution. This is true not only for Africa but also for other continents, making it necessary to have a better global mechanism for SDI implementation monitoring.

In order to improve the SDI implementation in Africa, the human components (policy, people) are key as they form the basis on which the technical components or physical infrastructure (data, access network), also essential to a successful SDI, can be efficiently used. We therefore recommend putting in place a proper political mechanism to support a continental SDI. UNECA already tries to do it through the CODIST meetings for several years but increased attendance and more commitment from African countries are needed. Besides, great opportunities lie in the cooperation among African and European institutions through for instance FP7 and H2020 framework projects.

The third objective was to compare the situation of Africa in terms of SDI status to the rest of the world. As demonstrated, a lot of efforts still need to be put in place to improve most of SDI components as well as a better SDI statistical information monitoring. This is true for Africa but also in other places of the World where regional SDI monitoring is strongly dependant on a regional integrated political vision. The success of the European SDI is mostly due to a strong political will translated through the INSPIRE directive. The discussion focused on the transposability of this European model to Africa and the conclusion is that this is not possible given the different nature of the key political institutions. Nevertheless, other solutions to improve SDI implementation in Africa have been proposed based on Africa's assets. It is important to reiterate such a survey again in a few years to see how the SDI implementation evolves in Africa compared to other continents.

The fourth objective of our study was to suggest some ways for improving the SDI implementation and monitoring in Africa. An important asset in Africa is the presence of UNECA that is already coordinating SDI activity on the continent as well as an initiative such as AfriGEOSS. UNECA and Africa in general would greatly benefit from a re-enforced mandate of UNECA in terms of continental SDI authoritative institution, as it is the key continental leader to implement SDI and SDI monitoring solutions. Other elements such as involvement of Africa in international projects with geographic components, open data growing political trend, and online capacity building are opportunities that are worth supporting and re-enforcing in Africa. All these elements are more dependent on international decisions (e.g. UN for UNECA, 
network of institutions for participation in international projects) than national or regional ones. Progresses at the continental level should help overcoming the regional and national political barriers influencing SDI policy and status.

\subsection{Final Recommendations}

Our final recommendations to improve SDI implementtation in Africa are then to (1) obtain more political commitment to SDI from African governments, which might require more Earth Observation dissemination and promotion; (2) to reinforce the role of UNECA as the officially recognized continental SDI leader institution and give it the necessary resources to put in place a proper SDI implementation strategy in Africa; this could for example be done in the framework of the AfriGEOSS initiative; (3) to establish a proper African SDI online monitoring tool that would for example contain online SDI monitoring surveys, or a centralized visual mechanism for monitoring SDI status of African countries through online comparative maps, for example through a regional observatory that could be hosted at UNECA; this should create incentives for countries to perform better than the others; and (4) to establish a capacity building program on SDI at national and continental level.

Acknowledgments. This work was supported by the European Commission through the seventh research framework funded projects AFROMAISON (Grant agreement no 266379) and EOPOWER (Grant agreement no 603500). The views expressed in the paper are those of the authors and do not necessarily reflect the views of the institutions they belong to. The boundaries and names shown on the maps do not imply official endorsement or acceptance by the authors. We thank three anonymous reviewers for their helpful comments on an earlier version of this manuscript.

Supporting Material. This paper contains supporting materials which are available online at http://www.iseis.org/jei/download/Supplem ent_201500325.docx.

\section{References}

AEGOS (2011). AEGOS project. http://www.aegos-project.org.

African Development Bank (2014). Open data for Africa. http:// www. afdb.org/en/knowledge/statistics/open-data-for-africa/.

Afromaison (2011). The Afromaison project. http://www.afromaison. net.

Afromaison (2013). Africa broker. http://afromaison.grid.unep.ch:80 80/gi-cat/gi-portal.

Clarke, D., Holland, P., Nairn, A., Swift, A., and Robertson, D. (1999). The Contribution of the Global Map to a GSDI. Australian Surveying and Land Information Group.

Delgado Fernandez, T., Lance, K., Buck, M., and Onsrud, H.J. (2005). Assessing an SDI Readiness Index, FIG Working Week 2005 and GSDI-8. Cairo, Egypt: 10.

ECOWREX (2014). ECOWREX map viewer. http://www.ecowrex. org/?q=node/906.

Eelderink, L. (2006). Toward key variables to assess National Spatial Data Infrastructures (NSDIs) in developing countries. MSc, Geographical Information Management and Application (GIMA).

Eelderink, L., Crompvoets, J., and de Man, E. (2008). Chapter 15:
Towards key variables to assess National Spatial Data Infarstructures (NSDIs) in developing countries. A Multi-View Framework to Assess SDIs, Rajabifard, A., Van Loenen, B., and Fernández, T. D., Wageningen University, RGI.

EIONET (2012). EIONET dataflow. http://www.eionet.europa.eu/ dataflows/pdf2012/.

EIS-Africa (2002). Geo-Information Supports Decision-Making in Africa: an EIS-Africa Position Paper.

EIS-Africa (2014). EIS-Africa overview. http://www.eis-africa.org/.

El-Askary, H., Park, S., Ahn, M., Prasad, A., and Kafatos, M. (2015). On the Detection and Monitoring of the Transport of an Asian Dust Storm Using Multi-sensor Satellite Remote Sensing. J. Environ. Inf., 25(2): 99-116. http://dx.doi.org/10. 3808/jei.201500306

EOPOWER (2014). The EOPOWER project. http://eopower.eu.

ESA (2013). Monitoring and managing Africa's water resources. http://www.esa.int/Our_Activities/Observing_the_Earth/Monitorin g_and_managing_Africa_s_water_resources.

ESA (2014). ESA Global Land Cover Map. http://www.esa.int/ Our_Activities/Observing_the_Earth/Space_for_our_climate/ESA _global_land_cover_map_available_online.

ESSILab (2014). GI-Cat tool. http://www.essi-lab.eu/do/view/GIcat/ Web Home.

European Commission (2013). INSPIRE geoportal. http://inspire-geo portal.ec.europa.eu/.

European Commission (2013). INSPIRE Member State Contact Points. http://inspire.ec.europa.eu/cms/contactpoints.cfm.

European Commission (2014). INSPIRE spatial data themes. http://in spire.ec.europa.eu/index.cfm/pageid/2/list/7.

European Parliament (2007). Directive 2007/2/EC of the European Parliament and of the Council of 14 March 2007 establishing an Infrastructure for Spatial Information in the European Community (INSPIRE). Official Journal of the European Union.

FAO (2013). Africover. http://www.glcn.org/activities/africover_en. jsp.

FGDC (2014). National Spatial Data Infrastructure. http://www.fgdc. gov/nsdi/nsdi.html.

GEO (2010). Crafting geoinformation: the art and science of Earth observation.

GEO (2013). Geonetcast. http://www.earthobservations.org/geonet cast.shtml.

GEO (2014). AfriGEOSS. http://www.earthobservations.org/art_019_ 002.shtml.

Giff, G. (2006). The value of performance indicators to Spatial Data Infrastructure development. In Proceedings of International Conference on Global Spatial Data Infrastrucure (GSDI9), pp. 3-11, Santiago, Chile.

Giuliani, G., Lacroix, P., Guigoz, Y., Bigagli, L., Ray, N., and Lehmann, A. (2014). Bringing GEOSS Services into Practice, GIS Open Source Workshop Material.

Giuliani, G and Peduzzi, P. (2011). The PREVIEW Global Risk Data Platform: a geoportal to serve and share global data on risk to natural hazards. Nat. Hazards Earth Syst. Sci., 11(1): 53-66. http://dx.doi.org/10.5194/nhess-11-53-2011

Giuliani, G., Ray, N., and Lehmann, A. (2013). Building Re- gional Capacities for GEOSS and INSPIRE: a journey in the Black Sea Catchment. Int. J. Adv. Comput. Sci. Appl., 3(3): 19-27. http://dx. doi.org/10.14569/specialissue.2013.030302

GSDI (2011). The SDI Africa Discussion List. http:/lists.gsdi.org/ mail-man/listinfo/sdi-africa.

GSDI (2012). SDI-Africa Newsletter. http://www.gsdi.org/newsletters-Africa.

Idrees, M.O., Saeidi, V., Yusuf, Y.A., and Rashid, A. (2012). Comparing Approaches and Strategies for NSDI Implementation Between the Developed and Developing World. Int. J. Spat. Data Inf. 
Res.

Koch, H., Liersch, S., and Hattermann, F. (2013). Integrating water resources management in eco-hydrological modelling. Integrated Water Resources Management in a Changing World: Lessons Learnt and Innovative Perspectives, 13.

Makanga, P. and Smit, J. (2010). A Review of the status of Spatial Data Infrastructure Implementation in Africa. South Afr. Compu. J., 45: $18-25$

Masser, I. (1998). The first generation of national geographic information strategies. Proceedings of Selected Conference Papers of the Third Global Spatial Data Infrastructure Conference, Camberra, Australia.

Mazzetti, P., Nativi, S., Santoro, M., and Boldrini, E. (2014). Big Data challenges and solutions in building the Global Earth Observation System of Systems (GEOSS). In EGU General Assembly Conference Abstracts, Vol. 16, p. 13855.

Monett, H.Á. and McLeod, P. (2013). Spatial Data Infrastructure (SDI) Manual for the Americas. Tenth United Nations Regional Cartographic Conference for the Americas, New-York, USA.

Najar, C., Rajabifard, A., Williamson, I.P., and Giger, C. (2007). A framework for comparing Spatial Data Infrastructures on the basis of web services and metadata management: an Australian-Swiss case study.

NASA (2013). Safari2000.

Nativi, S. and Bigagli, L. (2009). Discovery, mediation, and access services for earth observation data. Selected Topics in Applied Earth Observations and Remote Sensing, IEEE Journal of, 2(4): 233-240. http://dx.doi.org/10.1109/JSTARS. 2009.2028584

Nativi, S., Craglia, M., and Pearlman, J. (2012). The brokering approach for multidisciplinary interoperability: A position paper. Int. J. Spat. Data Inf. Res., 7: 1-15. http://dx.doi.org/10.2902/17 25-0463.2012.07

Nebert, D.D. (2008) Developing Spatial Data Infrastructures: The SDI Cookbook. http://www.gsdidocs.org/GSDIWiki/index.php/Ma in_Page.

Rajabifard, A. (2002). Diffusion for Regional Spatial Data Infrastructures: particular reference to Asia and the Pacific, University of Melbourne.

Rajabifard, A., Williamson, I.P., Holland, P., and Johnstone, G. (2000). From Local to Global SDI initiatives: a pyramid of building blocks. 4th Global Spatial Data Infrastructure Conference, Cape Town, South Africa.

Schwabe, C. and Govender, S. (2009). Getting geoinformation and spatial data infrastructure (SDI) to work for Africa: the rationale behind AESI-ALIGN. Proceedings of GSDI 11 world conference, 15-19 June, Rotterdam.

SERVIR-Africa (2014). SERVIR-Africa overview. https://www.servir -global.net/Africa.aspx.
Steudler, D., Rajabifard, A., and Williamson, I. (2008). Evaluation and Performance Indicators to Assess Spatial Data Infarstructure Initiatives. A Multi-View Framework to Assess SDIs, 193.

Su, L., Christensen, P., and Liu, J. (2013). Comparative study of water resource management and policies for ecosystems in China and Denmark. J. Environ. Inf., 21(1): 72-83. http://dx.doi.org/10. 3808/jei.201300234

UNECA (2013). Committee on Development Information, Science and Technology. http://www.uneca.org/codist.

UNEP (2014). UNEP-live. http://uneplive.unep.org/.

UNIGIS (2014). UNIGIS overview. http://www.unigis.net/.

UNITAR (2014). Haiti Earthquake 2010: Remote Sensing based Building Damage Assessment Data. http://www.unitar.org/unosat/ haiti-earthquake-2010-remote-sensing-based-building-damage-ass essment-data.

University of Illinois (2014). Daily state of the cryosphere. http://arc tic.atmos.uiuc.edu/cryosphere/.

USGS (2010). Shuttle Radar Topography Mission. http://srtm.usgs. gov/.

USGS and USAID (2013). FEWS NET Africa Data Portal. http://ear lywarning.usgs.gov/fews/africa/index.php.

Van Loenen, B. and van Rij, E. (2008). Assessments of Spatial Data Infrastructures from an organisational perspective. A Multi-View Framework to Assess SDIs. Melbourne: University of Melbourne, 173-192.

Vandenbroucke, D. (2009). Inspire \& NSDI State of Play: Methodology. D 1.1-Report on Methodology.

Vandenbroucke, D. (2010). INSPIRE \& NSDI SoP. D4.1-Summary report regarding the results of the European Assessment of 34 NSDI (first year), September 2010.

Vandenbroucke, D. (2011). INSPIRE \& NSDI SoP. D4.2-Summary report regarding the results of the European Assessment of 34 NSDI (first year), September 2011.

WHO. Global Health Observatory Data Repository. http://apps.who. int/gho/data/node.main.

Wikipedia (2015). Open data. https://en.wikipedia.org/wiki/Open_ data.

World Bank (2013). World Bank data. http://data.worldbank.org/to pic/economy-and-growth.

Xia, X.H., Wu, Q., Mou, X.L., and Lai, Y.J. (2014). Potential impacts of climate change on the water quality of different water bodies. $J$. Environ. Inf., 25(2): 85-98. http://dx.doi.org/10.3808/jei.201400 263

Yang, W. and Yang, Z. (2014). Evaluation of Sustainable Environmental Flows Based on the Valuation of Ecosystem Services: a Case Study for the Baiyangdian Wetland, China. J. Environ. Inf., 24(2): 90-100. http://dx.doi.org/10.3808/jei.201400276 